\title{
Erratum to: Language generativity, response generalization and derived relational responding
}

\author{
Ian Stewart $^{1} \cdot$ J. McElwee ${ }^{1} \cdot$ S. Ming ${ }^{1}$
}

Published online: 7 April 2017

(C) Association for Behavior Analysis International 2017

\section{Erratum to: Analysis Verbal Behav \\ DOI 10.1007/s40616-016-0060-8}

The Analysis of Verbal Behavior, 2013, 29, 137-155

The first line of the second paragraph should read:

Language generativity might be described as the ability to produce sentences never before said, and to understand sentences never before heard - to produce an effectively infinite variety of utterances and understand similarly various utterances.

The online version of the original article can be found at http://dx.doi.org/10.1007/s40616-016-0060-8.

Ian Stewart

ian.stewart@nuigalway.ie

1 National University of Ireland, Galway, Galway, Ireland 